\title{
Análisis y reflexiones \\ sobre el control de constitucionalidad de las leyes
}

\author{
Enrique Díaz Bravo**
}

Recibido: mayo de 2015

Aprobado: octubre de 2015

DOI: 10.22395/ojum.v15n30al

\section{RESUMEN}

El autor hace un análisis descriptivo desde la perspectiva histórica de los sistemas denominados clásicos de control de constitucionalidad de las leyes, norteamericano y europeo, abordando sus principales características e implicancias en cada región, para luego estudiar las particularidades de cada modelo, señalando las herramientas que a juicio del autor constituyen elementos integradores de los nuevos modelos de control de constitucionalidad.

Palabras clave: control constitucional, justicia constitucional, tribunal constitucional, supremacía, jurisdicción constitucional.

Este artículo tiene su origen en el trabajo de fin de Máster presentado por el autor en el Máster en Derecho Constitucional de la Universidad de Sevilla, bajo la dirección del Prof. Dr. Javier Pérez Royo. Recientemente ha sido actualizado para esta publicación, incorporando, además, nuevas fuentes y referencias bibliográficas.

* Universidad Santo Tomás (CHILE). Abogado. Licenciado en Ciencias Jurídicas y Sociales, U. Central de Chile; máster en Derecho Constitucional, U. de Sevilla; máster en Estudios Hispánicos, U. de Cádiz; egresado Máster en Evaluación de Políticas Públicas, U. Internacional de Andalucía; doctorando en Derecho, U. de Castilla-La Mancha. Investigador predoctoral Erasmus+, Università di Bologna. Profesor de Derecho Administrativo y Contratación Administrativa, y director Magíster en Derecho Público, U. Santo Tomás, Chile. Correo: enriquediazbr@santotomas.cl. 


\section{Analysis and Reflection on the Control of Constitutionality of Laws}

\section{ABSTRACT}

The author makes a descriptive analysis from the historical perspective of systems known as classic control systems for constitutionality of laws (American and European), addressing their main characteristics and impact on each region. The author then analyzes the characteristics of each model, describing the tools that, at his judgment, constitute integrating elements of the new constitutionality control models.

Key words: constitutional control; constitutional justice; constitutional court; supremacy; constitutional jurisdiction. 


\section{INTRODUCCIÓN}

En este trabajo se presenta una recapitulación histórica sobre el control de constitucionalidad de las leyes, materia que durante largo tiempo ha generado debate sobre si este debía ser conforme al modelo norteamericano o, bien, conforme al modelo denominado europeokelseniano, lo que permitirá indagar sobre las causas que fueron determinantes en la elección de un modelo u otro en cada región. Igualmente, se examinarán las diferencias principales que destacan en la clásica polaridad de sistemas de control de constitucionalidad.

Como es de común acuerdo en la doctrina, se ha pasado de una polaridad a una integración de los sistemas denominados clásicos de control de constitucionalidad de las leyes, destacando ciertos elementos que confirman dicha tendencia e incluso ciertas instituciones de carácter procesal que han permitido a la justicia constitucional desempeñar un rol activo en el cumplimiento de sus objetivos, principalmente para garantizar la Supremacía de la Constitución, y por consiguiente los derechos de los individuos, como ocurre en el caso de la cuestión de constitucionalidad

Sin embargo, no necesariamente la coincidencia de elementos de los sistemas de control determina una fusión de ambos, toda vez que, como se verá, existen ciertos rasgos distintivos que nos hacen pensar en tantos modelos actuales de justicia constitucional como ordenamientos jurídicos en los que está presente.
En la actualidad son ampliamente reconocidos en los Estados democráticos, constituyendo una especie de norma de calidad, los principios de soberanía popular, legitimación democrática de los poderes constituidos, reconocimiento y protección de los derechos fundamentales, consagración de un conjunto de principios y valores constitucionales, aplicación directa de la Constitución en cuanto norma fundamental, y garantías fundamentales de resguardo y protección de la Constitución como norma jurídica. Es más, actualmente las garantías constitucionales, en particular el control de constitucionalidad de las leyes, constituyen un elemento que no se aleja de la polémica, encontrando posiciones que consideran la justicia constitucional como un elemento antidemocrático, y otras posiciones, de las que formo parte, que consideran que la justicia constitucional es un distintivo de los regímenes democráticos, por lo que la necesidad de su análisis es del todo vigentel.

\footnotetext{
Garrorena ha repuesto la discusión referente a la legitimidad y compatibilidad de la justicia constitucional con la democracia y lo hace presentando el problema producto de la evidente tensión de ella con esta. Sostiene que dicha tensión es "constitutiva de este instituto, porque aceptar -como debe ser- que en todo régimen verdaderamente constitucional ha de existir un juez sobre la ley es afirmar a la vez que en nuestras democracias los poderes democráticamente constituidos, y por lo tanto la clase política que los habita, no tienen la última palabra" $(2015,36)$. Compartiendo dicho planteamiento considero que el mismo contiene la base y justificación para que se justifique, compatibilice y, es más, legitime la existencia del instituto de la Justicia Constitucional en la democracia, ya que los pactos constituyentes, que se expresan en las constituciones, son permanentemente golpeados para sustituirlos mediante las simples mayorías políticas momentáneas y muchas veces
} 
Para la exposición del artículo se presenta, en primer lugar, un análisis conceptual que fijará el margen de trabajo por medio de una estructura de elementos que se consideran los más relevantes, para lo cual se enunciarán conceptos de diversos autores para arribar a uno de elaboración propia. En segundo lugar, un análisis descriptivo de los modelos europeo y norteamericano de control de constitucionalidad, para, en un tercer lugar, realizar un análisis crítico de cada uno, destacando sus propias características. Con ello se fijarán las bases para desarrollar los nuevos modelos y herramientas existentes de control de constitucionalidad, lo que constituye el resultado principal del trabajo, pretendiendo aportar al desarrollo de los mecanismos ordinarios de protección de la supremacía constitucional. Para los resultados que se presentan realizamos

dichas mayorías se agrupan para defender intereses corporativos alejados de la ciudadanía. Así, y siguiendo a Pérez Royo (1988), considero que la presencia de la justicia constitucional nos indica que algo no va bien en el sistema constitucional, una señal de maña salud de la democracia, sistema por tanto que requiere de garantías que permiten al pacto constituyente mantener su supremacía en el ordenamiento constitucional, la que se ve en duda producto de los embates diarios de aquellos que pretenden sustituir la voluntad general por su propia voluntad. Es por ello que compartimos plenamente lo sostenido por Peña Torres (2014) cuando sostiene que "Si la democracia es hoy, por esencia, un medio para la plena defensa y promoción de los derechos de las personas y grupos, la tradicional objeción democrática a la actuación de los Tribunales y Salas Constitucionales se va debilitando, por sí misma, pues el constitucionalismo de hoy ya no sólo puede ser mirado como una técnica para favorecer la limitación del poder, sino que, por sobre todo, como un mecanismo esencial para la defensa de los derechos en democracia". un análisis a la luz de la doctrina y jurisprudencia comparada.

\section{JUSTICIA CONSTITUCIONAL. PRECISIONES CONCEPTUALES}

En términos generales, considero que el rol de la justicia constitucional, mediante la interpretación del texto fundamental, es el de una garantía constitucional para proteger la supremacía de la Constitución en el ordenamiento jurídico, es decir, la propia Constitución es la máxima manifestación del acuerdo político que la sociedad decide en un momento histórico determinado; dicha decisión contiene esencialmente la forma de organizar la sociedad con el objeto de alcanzar una convivencia pacífica fijando un conjunto de mínimos que permitan a cada uno de los miembros un pleno ejercicio y desarrollo del catálogo de derechos y libertades que se acuerden, catálogo que debe ser el más extenso posible y compatible con el mismo catálogo para toda la sociedad ${ }^{2-3}$.

Es por ello que para preservar la decisión contenida en la Constitución el Constituyente incorpora mecanismos de protección para asegurar la posición suprema de la Constitución en el ordenamiento

2 Sobre la materia del contenido del acuerdo para organizar la sociedad véase la obra Teoría de la justicia de J. Rawls (1993).

3 La proyección y protección de los derechos de los individuos juega un rol central en el Derecho Constitucional, siendo la dignidad del individuo el punto de inicio y término de todo el ordenamiento jurídico. Sobre la materia véase el trabajo: "El bloque constitucional de derechos en Chile, el parámetro de control y consideraciones comparativas con Colombia y México: doctrina y jurisprudencia" de Nogueira Alcalá (2015). 
jurídico, todo con la intención de asegurar que su decisión prime y perdure durante el tiempo, hasta que la misma sociedad, pero otra generación, determine sustituir la decisión.

En la doctrina se han elaborado diferentes conceptos que responden, muchas veces, a distintas perspectivas para abordar la temática del mecanismo ordinario de protección de la supremacía constitucional, algunas de las cuales considero son las más importantes y que se desarrollan a continuación, y que se estructuran, primero, como limitación del poder político; segundo, como técnica de protección, y, tercero, como procedimiento.

En primer término, desde la perspectiva de la justicia constitucional como limitación del poder y como herramienta para someterla a la Constitución, destaca Cappelletti que la justicia constitucional se utiliza para "indicar que el poder del gobierno está limitado por normas constitucionales y que se han creado procedimientos e instituciones para hacer cumplir esta limitación" (1986, p. 12).

Como una técnica de protección frente a los ataques de los órganos denominados constituyentes constituidos, Tania Groppi afirma que la justicia constitucional es aquella "técnica de defensa jurisdiccional de la Constitución frente a actos y comportamientos de los poderes públicos, incluida la Ley del Parlamento" (2005, p. 35).

Desde una perspectiva procedimental, la justicia constitucional se expresa o actúa por medio de la denominada jurisdicción constitucional que, según Lucas Verdú, es aquella jurisdicción que tiene por objeto "... decidir, de modo imparcial, con arreglo al derecho objetivo y mediante los procedimientos y órganos especiales establecidos, el cumplimiento, tutela y aplicación de las normas jurídicas constitucionales (escritas y consuetudinarias") (1986, p. 690). En la misma perspectiva de la jurisdicción encontramos la opinión de Aragón Reyes quien la entiende como "la actividad judicial de la aplicación de la Constitución y la realizan tanto el Tribunal Constitucional como los jueces y tribunales ordinarios, pues la Constitución es norma jurídica inmediatamente aplicable, de la que emanan derechos y obligaciones judicialmente exigibles" (2006, p. 3).

Por su parte, H.-P. Schneider (1982) incorpora las diversas perspectivas planteadas sobre la justicia constitucional sosteniendo que su esencia se puede relacionar con la concepción de un Estado judicial, bien, como un elemento u órgano constitucional o, bien, como centro protector de los derechos individuales, o en el control de las leyes, o incluso, en la garantía de la Constitución. Por otra parte, podría ser considerado como un "cuarto poder", o como una cuarta instancia para otros, si son los aspectos institucionales de la jurisdicción constitucional lo que se considera como prioritario. En la misma línea de incorporar las diferentes perspectivas encontramos el concepto de Peña Torres cuando sostiene que:

La justicia constitucional ha sido concebida como el conjunto de normas, de órganos y de pro- 
cedimientos destinados a dar efectiva concepción al principio de supremacía de la Constitución, entendida como un conjunto de valores, principios y reglas que fijan el compromiso esencial de una sociedad en cuanto a su organización y destino (2012, 17).

Así las cosas, asumiendo las diferentes perspectivas enunciadas, puedo sostener que la justicia constitucional es aquella garantía ordinaria que el Constituyente democrático incorpora en la Constitución para resguardar su decisión, asegurando que aquella se mantenga como la norma suprema del ordenamiento jurídico que somete al poder a sus términos, mediante los órganos y procedimientos que se estimen más adecuados para cada sociedad y momento político.

De acuerdo con lo indicado en el párrafo anterior, corresponde desarrollar cuáles son los modelos para asegurar que la Constitución se mantenga en su posición suprema y sea aplicada con primacía en el ordenamiento jurídico, lo que se manifiesta por medio de los modelos de control de constitucionalidad.

\section{DEL CONTROL DE CONSTITUCIONALIDAD Y SUS MODELOS}

El control de constitucionalidad tiene por objeto verificar que no existan normas que contradigan al texto fundamental, ya sea que se efectúe el control en una etapa previa a la entrada de la propuesta normativa al ordenamiento jurídico (control $a$ priori) o, bien, cuando una norma aplicada a un caso concreto provoca la vulneración de la Constitución (control a posteriori).

Es mediante la jurisdicción constitucional, en cualquiera de sus modalidades, que el ordenamiento se protege de ello, en el caso de existir aspectos contradictorios con la Constitución, al disponer que estos sean declarados inconstitucionales e impedir, en definitiva, que adquieran la calidad de normas o al expulsarlos del ordenamiento jurídico.

Tradicionalmente se ha indicado la existencia de dos modelos de control de constitucionalidad como garantía de la supremacía de la Constitución, en sentido amplio; uno, procedente de los Estados Unidos de Norteamérica, cuyo principal antecedente es la sentencia del Juez Marshall en el caso Marbury contra Madison, y otro, de procedencia europea, elaborado por el austriaco Hans Kelsen. Así, el primero es producto del positivismo jurídico y coronación del principio de legalidad, mientras que el segundo plantea a la Constitución como ley superior en cuanto tabla de valores (Groppi 2005, p. 33); todo ello producto de sus disimiles orígenes cuestión que se desarrollará a lo largo del presente trabajo.

Ambos modelos, sin embargo, tienen por objeto garantizar la supremacía de la Constitución: en Norteamérica la función es desempeñada por el Poder Judicial, mientras que en el modelo europeokelseniano se realiza por un organismo ad hoc, Tribunal o Corte Constitucional, que tiene como competencia natural, y justificadora de su existencia, el control 
de constitucionalidad de las leyes, ya que en un ordenamiento jurídico donde la Constitución haya sido respetada no es necesaria la creación de este órgano artificial.

Respecto a la diferencia entre los modelos de control de constitucionalidad Fernández sostiene que "... conviene no olvidar que las divergencias entre ambos modelos de control de constitucionalidad dimanan de unos presupuestos histórico-políticos e ideológicos contrapuestos que constituyen la última, y más profunda ratio de su bipolaridad" (2004, p. 23). Así, la dificultad histórica fundada en una posición política de la sociedad es el control del poder político, expresado en todas sus formas y manifestado por distintas vías, ya sea a través de la ley o a través de los actos de la Administración, finalizando la dificultad en la determinación de su lugar de residencia ${ }^{4}$.

4 Como una expresión del sustento ideológico encontramos las ideas del liberalismo en Inglaterra, principalmente en los planteamientos de Locke (2002), quien sostiene la igualdad de los hombres y su libertad. Todos los individuos se encuentran sometidos y limitados de igual forma por una ley natural, de modo que los gobiernos deben respetar dicha ley. Cabe contextualizar que esta tesis de la superioridad de una ley natural, que podría expresarse en el common law, fue sobrepasada por la soberanía parlamentaria, estableciéndose así la superioridad de las leyes, y por supuesto de su irreversibilidad por otro órgano sin la representación que el Parlamento tenía. De este modo, en el caso inglés el sistema se articuló con base en el Parlamento, como órgano donde confluían los distintos estamentos, de modo de garantizar, al menos formalmente en un comienzo, la representatividad de los titulares de la soberanía. Así, la ley, como manifestación del Parlamento provocó que la función judicial quedara sin la posibilidad de actuar en contra de la omnipotencia de la ley.
Uno de los principales instrumentos limitadores del poder político fue la Declaración francesa de Derechos de 1789, en donde se reconocen en forma expresa solo dos poderes, el Legislativo y el Ejecutivo; la justicia no se menciona como poder, pero no se dejan de considerar las garantías de los derechos. Es la ley la que acompaña a los derechos, desplazando incluso a la justicia, ya que las libertades y garantías son según y conforme a la ley. Entonces, es la ley la que puede apreciar los atentados que se provocaren a los derechos de libertad, tanto públicos, del ejecutivo inclusive, o privados. Es la ley que por la sola fuerza de la Declaración de Derechos tenderá a que la actividad legislativa se encuentre al servicio de la libertad.

Se provoca gracias a la Declaración de Derechos una separación de poderes de gran fuerza que ratifica el Poder Legislativo en el primer orden de poderes, un ejecutivo después y un judicial como vagón de cola. Se plantea de forma categórica que incluso el judicial sería solo una función que ha de consistir en la aplicación de la ley lo que es mera dependencia del Poder Ejecutivo, con lo cual se recalca que no hay más que dos poderes: el que hace la ley y el que la ejecuta. Es entonces un importante factor que explica la razón de la adopción, en Europa, de un sistema distinto, el relativo al principio de separación de poderes y el rol del Poder Judicial. Mientras que en Norteamérica el juez era parte del proceso de liberación de Inglaterra, el juez en Europa era considerado como un funcionario del Rey, sien- 
do el Parlamento el promotor y protector de los derechos y garantías de libertad.

En Europa el sistema difuso no encuentra cabida, por lo que se construye el denominado "privilegio del legislador" que consiste en que debe ser un órgano especial el que pueda controlar los actos del poder legislativo en cuanto órgano de representación de la soberanía, distinto de los jueces de carrera, con el objeto, como sostiene Zagrebelsky (1995), por una parte, de participar en el nombramiento de los jueces especiales que controlarán sus actos, y por otra, debido al propio principio de separación de poderes, ya que los jueces de carrera tienen la obligación de reconocer y someter su actuación a las normas emanadas del Legislativo, mientras conserven su fuerza vinculante. Es por ello que el sistema europeo está determinado por la desconfianza al sistema de la judicatura, buscando la supremacía del Parlamento, en tanto órgano de representación democrática, dando así mayor seguridad jurídica, ya que los jueces representaban los intereses de una clase -la aristocracia-, por lo que de entregarles la facultad de controlar la constitucionalidad se podría ver afectada la más básica premisa de la justicia constitucional, el control del poder político para que tanto mayorías como minorías sean respetadas, según disponen la Constitución y el ordenamiento jurídico 5 .

5 Como sostiene Almagro "La Justicia Constitucional -encarnada en un TC- es la consecuencia natural de las dificultades de consolidar un régimen democrático por medios acordes a la lógica de la división de poderes propia del Estado Constitucional y, por tanto, su existencia obedece en principio a síntomas de una cierta debilidad constitucional" (2013, p. 192).
Como sostiene Lucas Verdú (1986), el proceso de establecimiento de la justicia constitucional en Europa es realizado en un marco contextual crítico, toda vez que el concepto liberal de que un tribunal sería quien vendría a resolver los grandes conflictos es opacado por la crisis del parlamentarismo y la extrema politización de toda la sociedad que considera la justicia constitucional como inútil para enfrentarse y frenar los totalitarismos tanto de izquierda como de derecha. El legislador se convierte en la gran amenaza a los individuos, a través de la ley, con la cual puede gobernar a su antojo, de modo que el Estado de derecho queda aniquilado, y sometido a las mayorías momentáneas. Por ello, la vieja idea de la supremacía de la Ley como expresión de la voluntad general en los términos rousseaunianos fue reemplazada por la idea de la constitucionalidad del ordenamiento, donde la aplicación directa de los preceptos constitucionales, tanto sus normas como sus valores y principios, permiten proyectar sobre la sociedad todo su contenido material y sustantivo.

\subsection{Modelo judicial norteamericano}

En la Constitución de los Estados Unidos de 1787 no se establece expresamente el control de constitucionalidad de las leyes, aun cuando se establecía la superioridad de la Constitución y las leyes federales. Allí es donde radica la importancia del juez Marshall, quien, en 1803, por medio de resolución del Tribunal Supremo de los Estados Unidos en el caso Marbury contra Madison, fija el punto de partida del control de constitucionalidad de las 
leyes bajo el supuesto de la supremacía de la Constitución. De esto no hay duda ni discusión en la doctrina; no obstante, cabe destacar ciertos antecedentes que informan la construcción del referido juez.

En El Federalista, número 78 (Hamilton 2001), existen antecedentes que, sin lugar a dudas, sirven de referencia a la sentencia del juez Marshall, y donde Hamilton manifiesta:

[...] los tribunales han sido concebidos como un cuerpo intermedio entre el pueblo y la legislatura, con la finalidad, entre otras varias, de mantener a esta última dentro de los límites asignados a su autoridad. La interpretación de las leyes es propia y peculiarmente de la incumbencia de los tribunales... (en caso de discrepancia) debe preferirse la Constitución a la ley ordinaria, la intención del pueblo a la intención de sus mandatarios...

Por otra parte, Pérez Royo (1987, p. 27) sostiene que la decisión del juez Marshall puede ser considerada como el hecho que marca el inicio del control de constitucionalidad de las leyes, pero puede también ser considerada como el punto de llegada de un proceso que estuvo precedido por diversos acontecimientos:

a) La Gloriosa Revolución Inglesa del siglo XVII, que destaca, para estos efectos, como un proceso en que se le exige responsabilidad penal a James II por la violación de la Constitución, de modo de hacer efectivo y legítimo el derecho de resistencia; b) En el siglo XVIII se producen dos episodios: el ejercicio del derecho de petición por la ciudad de Kent, y la Septennial Bill, en los que se plantea la posibilidad de que los actos del legislativo, Cámara de los Comunes, pudieran ser inconstitucionales;

c) Los procesos en las colonias norteamericanas tanto, en primera instancia, contra el Parlamento inglés, como, en segunda instancia, frente a los poderes constituidos de diferentes Estados, en términos de distribución territorial, donde la discusión circulaba en torno a la supremacía de la Constitución sobre los poderes constituidos ${ }^{6}$.

Ahora bien, en particular, en la comentada sentencia del caso Marbury contra Madison (Suprema Corte U. S. 1803), se discutía si una ley emanada del Congreso y contraria a lo dispuesto en la Constitución podía mantenerse vigente en el ordenamiento jurídico y ser aplicada a un caso concreto $^{7}$. A John Marshall, presidente de la

6 A mayor ahondamiento, es posible encontrar antecedentes remotos del control de constitucionalidad, como relata Vile (2007, p. 453), en el Consejo de Revisión de la Constitución de Nueva York de 1777 , en las resoluciones de los primeros tribunales de los Estados y, sobre todo, en la Convención Federal en la que se manifestó que los jueces debían tener la facultad de ejercer control sobre el legislativo de forma que se evitara que este tomara decisiones ajenas a sus funciones impidiendo que las convirtieran en ley, de forma que tanto el veto como el control de constitucionalidad se convertían en manifestaciones de los poderes para controlar la funciones del legislativo.

7 Como antecedente histórico de la sentencia se debe tener presente que el Presidente saliente de los Estados Unidos, John Adams, el día anterior del término de su mandato presidencial, decidió sobre el nombramiento de 42 jueces de paz que 
Suprema Corte, le correspondió conocer del tema y al pronunciar su resolución sostuvo que:

La cuestión de si una ley común que repugna a la Constitución puede llegar a ser una ley válida, interesa profundamente a los Estados Unidos; pero afortunadamente no es tan intrincada como interesante. Nos parece que sólo es necesario tomar en cuenta ciertos principios ya por largo tiempo establecidos para decidirla.

En esta sentencia se establecieron dos principios: uno de carácter procesal, esto es, la falta de competencia de la Suprema Corte para conocer de asuntos que la ley no ha puesto, como Tribunal a quo, en la esfera de sus atribuciones, y otro, de carácter constitucional, que consiste en la facultad de controlar la constitucionalidad de la leyes en todos aquellos asuntos

ejercerían sus funciones en el Distrito de Columbia, para lo que emitió sus nombramientos en lo que se denomina midnight appointments, o nombramiento de último minuto. Estos nombramientos en vilo tenían por objeto mantener a jueces cercanos al partido federalista. El entonces, paradójicamente, Secretario de Estado, John Marshall, no logró notificar todos los nombramientos de los jueces de paz, por lo que los nombramientos pendientes debían, supuestamente, ser notificados por el nuevo Secretario de Estado, James Madison. Este no les dio curso, ya que la línea política del gobierno había cambiado con el nuevo Presidente del Partido Republicano, Thomas Jefferson. En virtud de lo anterior es que William Marbury, ciudadano a quien se le había negado el nombramiento, junto con otros afectados, presentó un requerimiento a la Suprema Corte, en la que solicitaba se requiriera al Secretario de Estado la notificación de los nombramientos correspondientes, en virtud de la Judiciary Act (Sección 13, de 1789) la que facultaba a la Suprema Corte a dictar resoluciones ordenando a la Administración de Gobierno. sometidos a su conocimiento, en tanto órgano judicial, lo que le permitiría a todo juez controlar la constitucionalidad de las leyes, innovando así por la vía interpretativa en la Constitución de dicho país.

Es, entonces, el razonamiento expresado en esta sentencia el hecho constituyente del paradigma del control de constitucionalidad de la ley, el que, combinando los conceptos de supremacía y rigidez ${ }^{8}$, establece que si una ley se encuentra en contradicción con la Constitución debe prevalecer esta última, provocando el deber del Poder Judicial de proteger la Constitución', manifestación de la supremacy clause, lo que sienta las bases para el control de constitucionalidad de las leyes,

8 En la sentencia de la Suprema Corte se aprecian dos pasajes que ratifican lo expresado: "¿Con qué objeto se consignan tales límites por escrito, si esos límites pudieran en cualquier tiempo sobrepasarse por las personas a quienes se quiso restringir? La distinción entre gobiernos de poderes limitados y los poderes ilimitados, queda abolida si los límites no contienen a las personas a las cuales les han sido impuestos y si lo prohibido y lo permitido se equipara. Este es un razonamiento demasiado obvio para dejar lugar a dudas y lleva a la conclusión de que la Constitución controla cualquiera acto legislativo que le sea repugnante; pues de no ser así, el Legislativo podría alterar la Constitución por medio de una ley común"; "O bien la Constitución es una ley superior inmodificable por medios ordinarios, o bien queda al nivel de las demás leyes del Congreso y como tales, puede ser alterada según el Legislativo quiera alterarla. Si el primer extremo de la alternativa es la verdad, entonces un acto legislativo contrario a la Constitución, no es una ley; si el segundo extremo de la alternativa es verdadero, entonces las constituciones escritas son intentos absurdos por parte del pueblo para limitar un poder que por su propia naturaleza es ilimitable" (1803).

9 "... los tribunales deben tomar en cuenta la Constitución y la Constitución es superior a toda ley ordinaria del Legislativo..." (Suprema Corte 1803). 
particularmente en los Estados Unidos de Norteamérica.

De este modo, es posible observar que la resolución del Tribunal Supremo de los Estados Unidos, dentro del conflicto político que se vivía por la reciente elección presidencial del país, crea, por medio de la interpretación constitucional, el control de constitucionalidad de las leyes que en virtud del principio de soberanía popular tiene por objeto garantizar la Constitución como manifestación del Poder Constituyente, no pudiendo ser objeto de modificación por medio de leyes ordinarias. Es finalmente, la construcción del control de constitucionalidad de las leyes, el momento donde el concepto de supremacía de la Constitución se afirma jurídicamente; antes era solo una discusión de carácter más bien político que respondía a las pasiones y mayorías del momento. Se inicia así, una nueva era en el control de poder, el denominado judicial review.

\section{Particularidades del modelo}

El modelo norteamericano de control de constitucionalidad de las leyes se caracteriza por los siguientes elementos distintivos:

1. Es un modelo difuso o descentralizado, ya que todo juez tiene competencia para ejercer el control de constitucionalidad.

2. Es incidental o concreto, debido a que se ventila durante un juicio principal que tiene una causa y un objeto distintos, en cuanto el juez se pronuncia por vía de excepción con ocasión de la aplicación de una ley en particular.

3. Es especial en sus efectos ya que solo se extiende inter partes, es decir, solo produce efectos la declaración de inconstitucionalidad en el caso concreto;

4. Es declarativo, pues la declaración de invalidez se aplica ex tunc, de modo retroactivo y se aplica directamente la Constitución, pero no se anula el precepto en cuestión ${ }^{10}$.

5. Sobre la accionabilidad del control de constitucionalidad, este puede ser iniciado de diferentes formas:

a. Por medio de la excepción de constitucionalidad, las partes en el proceso pueden defenderse de una ley que, siendo aplicable, adolezca de dicho vicio;

b. Un individuo puede solicitar directamente la declaración de inconstitucionalidad de una ley, de cuya aplicación resultan perjuicios para sí, y;

c. Por medio de la solicitud de una decisión aclaratoria, los particu-

10 Hans Kelsen (1949) sostenía que si un determinado ordenamiento jurídico no contiene alguna regla explicita que disponga lo contrario, existe la presunción, entonces, de que todos los órganos que aplican las leyes, tienen la facultad de rechazar la aplicación de leyes inconstitucionales, ya que se encuentran naturalmente llamados a verificar que la norma que deberían aplicar es efectivamente una ley, es decir que no es contraria a la Constitución. 
lares que en la aplicación de una ley encontraren dificultad podrán recurrir a un tribunal.

6. Los tribunales deberán tener presente, como sostiene D. Rousseau (2002, p. 110), entre otras, en el examen de constitucionalidad de una ley, las siguientes cláusulas:

a. Due process of law o garantía de debido proceso, de modo que es posible invalidar una ley si no han existido procedimientos regulares en protección de los derechos o garantías del recurrente.

b. Rule of reasonableness o cláusula de razonabilidad o ponderación, de modo que de no haber procedido con razonabilidad o ponderación entre el interés general y el de los particulares podría anularse la ley.

c. La cláusula de igualdad, garantía de todo ciudadano ante la posible afectación de sus derechos.

Finalmente, cabe consignar que el rol del Poder Judicial y sus funciones en el desarrollo del sistema de control de constitucionalidad, judicial review, es considerado como uno de los aspectos más relevantes del sistema de frenos y contrapesos como mecanismo de separación de poderes en los Estados Unidos de Norteamérica.

\subsection{El control de constitucionalidad de la ley en Europa}

En el caso europeo los inicios del control de constitucionalidad de las leyes se asocian a la Constitución austriaca de 1920. Sin embargo, como relata Fernández (2002, p. 1.), ya en la Constitución de Weimar de 1919 existe un instrumento procesal de resolución "de conflictos entre aquellos órganos que concurren a la formación de la voluntad estatal".

Hans Kelsen (2009, p. 339), ideólogo del control de constitucionalidad en Europa, sostiene que es la Constitución la que distribuye el poder, principalmente, al menos, entre el Gobierno y el Parlamento, por lo que se provoca una permanente tensión en el ejercicio de las competencias propias de cada uno de ellos frente al otro, de modo que se ponen en peligro las disposiciones establecidas en la propia Constitución. Es el límite de las competencias lo que provoca dicha oposición, por lo que resulta necesario que un órgano extraño y que "esté fuera de esa oposición y que bajo ningún aspecto sea partícipe del ejercicio del poder que la Constitución distribuye en lo esencial entre Parlamento y Gobierno. Que esa misma institución reciba un cierto poder es inevitable".

Kelsen desarrolla su posición entendiendo el rol de la justicia constitucional como un legislador negativo, contrariamente al sistema norteamericano que provoca el efecto de desaplicación de una ley en cada caso concreto sometido a conocimiento de un juez, de modo que la anulación de una ley de aplicación general tiene un carácter similar a la propia elaboración de la ley. Sostiene, por otra parte, la necesidad de la existencia de un defensor de la Constitución entendiendo por tal 
"... un órgano cuya función es defender la Constitución contra las violaciones. De ahí que se hable también y por regla general de una "garantía» de la Constitución" (2009, p. 291), planteamiento que da origen al modelo denominado concentrado de control constitucionalidad de las leyes. Kelsen considera que las garantías constitucionales son aquellos medios por los cuales se controla la constitucionalidad del comportamiento de aquellos órganos sometidos a la Constitución, para dar cumplimiento al principio de máxima juridicidad de la acción estatal, propia del Estado de derecho.

El austriaco Kelsen habría querido que el Tribunal Constitucional fuese complementario respecto al Poder Legislativo, en la función de legislador negativo, asumiendo la desconfianza frente a los jueces, y de ese modo proteger la función del Parlamento, sometiendo en todo momento el poder judicial a la Constitución. El carácter de legislador negativo está dado por los efectos generales de la anulación de una ley al ser declarada inconstitucional, iguales que los de una ley promulgada por el poder legislativo. Más que colegislador, negativo, lo considero como un órgano corrector, rectificador de la legislación que sea contraria a la fuente primaria y superior de todo el ordenamiento positivo; es entonces, por las razones esgrimidas, el último bastión de la Constitución, el que, de verse superado, se transformará necesariamente en la causa del colapso del sistema democrático constitucional.

Por otra parte, Kelsen (2009) consideraba que el peligro por falta de uniformidad en las cuestiones constitucionales era demasiado grande y que no podía dejarse entregado, al menos en Austria, al sistema de precedentes, stare decisis, en un país donde el sistema era determinado por el civil law y no por el common law.

A su vez, Pérez Royo (1987) sostiene que son tres factores los que inciden decisivamente en la decisión del constituyente europeo para introducir la garantía del control de constitucionalidad: primero, la necesidad de garantizar los pactos constituyentes en el sistema democrático, el que por su heterogénea conformación provoca desconfianza entre los actores, en especial a las mayorías parlamentarias; segundo, la efectiva protección a los derechos que se han plasmado en las nuevas constituciones, y tercero, la propia distribución territorial del poder, para mediar entre los poderes centrales con los periféricos en cada Estado.

\section{Particularidades del modelo}

El modelo austriaco o europeo-kelseniano tiene ciertas particularidades que permiten distinguirlo como un modelo autónomo; en especial, son notas distintivas:

1. Es un sistema concentrado o centralizado ${ }^{11}$ por encontrarse el control de constitucionalidad reservado a un órgano especialmente constituido para tal efecto.

"Mauro Cappelleti (1986) se refiere al modelo centralizado, cuando lo hace sobre el modelo concentrado europeo; y descentralizado para referirse al modelo norteamericano o judicial review. 
2. Es principal, porque la cuestión se ventila de forma independiente de toda otra.

3. Es general en cuanto la declaración de inconstitucionalidad produce efectos erga omnes, expulsando así la norma del ordenamiento jurídico.

4. Es constitutivo, sus efectos se aplican ex nunc, solo hacia el futuro, sin perjuicio de las sentencias y situaciones jurídicas del tiempo intermedio ${ }^{12}$.

Otro elemento distintivo son los efectos que provoca su sentencia; como sostiene García de Enterría (1988), el tribunal constitucional de origen kelseniano, en virtud de sus efectos ex nunc, se limita a confrontar dos normas igualmente abstractas, Constitución y ley, por lo que el vicio de inconstitucionalidad que surge, eventualmente, no provoca la nulidad ipso iure de la norma o disposición, sino que, al contrario, genera la posibilidad de anulabilidad, la que se concreta en la sentencia del Tribunal Constitucional, por lo que, según sostiene, es una

12 Pérez Royo (1987) ilustra con toda claridad la diferencia entre difuso y concentrado: "Difuso quiere decir lo contrario de concentrado. El Poder legislativo es un poder concentrado. El poder judicial es un poder difuso. El parlamentario no es el titular del poder legislativo, el titular del poder legislativo es el Parlamento. Por el contrario, el poder judicial no existe como un poder, sino que existe en la forma de miles de jueces y magistrados repartidos por todo el territorio del Estado, titulares cada uno de ellos individualmente del poder judicial. En consecuencia, al ser el control un control judicial, ello quiere decir que está uniformemente a disposición de todos y cada uno de los jueces integrados en el poder judicial. Esto quiere decir difuso". sentencia constitutiva sobre los hechos concretos en un verdadero litigio.

A mi juicio esto sería efectivo solo desde el punto de vista procesal, ya que las declaraciones del Tribunal Constitucional son más que un examen meramente mecánico de dos normas de distinto grado o jerarquía, sino que constituyen un conjunto complejo de interpretaciones que tienen como finalidad la salvaguarda de un conjunto de principios y valores que trascienden, muchas de las veces, a la norma formal.

\section{DESARROLLO DE NUEVOS MODELOS}

El legislador, que fuera considerado el mayor peligro para la democracia y para la Constitución, evoluciona a partir de la Segunda Guerra Mundial sometiéndose al imperio de la Constitución como Ley Suprema. Esto abre el camino para que los jueces tengan la posibilidad de participar en la estructura de control de constitucionalidad, y se abandona sí la desconfianza inicial que existía sobre las estructuras judiciales por considerarlas representantes de los intereses de una clase determinada; por ello, el carácter coadyuvante de los tribunales constitucionales para con el legislador, en su rol de legislador negativo, va disipándose, al incorporar a los jueces al sistema de defensa de la Constitución con las instituciones insinuadas. La cuestión de constitucionalidad, como manifestación máxima, se acerca así a los planteamientos del modelo norteamericano sin dejar atrás los rasgos clave del sistema europeo-kelseniano, a saber, primero, el 
órgano concentrado y único de control constitucional; segundo el monopolio de la declaración de inconstitucionalidad, y tercero, sus efectos erga omnes. Tal como opina García de Enterría (1988), en Europa se recibe el modelo norteamericano de jurisdicción constitucional aun cuando se incorpore en el ordenamiento constitucional bajo la fórmula centralizada.

Se produce entonces, como hito histórico, a partir de la Segunda Guerra Mundial, tal como desarrolla Fernández (2004), la relativización de los dos modelos clásicos producto de los efectos políticos posguerras; sin embargo, los rasgos más característicos de cada uno de los sistemas se encontraban relativizados con anterioridad; por ejemplo, la reforma constitucional austriaca de 1929, así como el propio sistema de justicia norteamericano han incorporado ciertos rasgos del modelo europeo con la reforma de 1925. El tertium genus entre los modelos europeo-kelseniano y el norteamericano provoca numerosas variables; sin embargo, se logran identificar determinados rasgos comunes.

Así, respecto a la relatividad del efecto de las sentencias de inconstitucionalidad del sistema estadounidense, cabe consignar que, producto de la regla de los precedentes (stare decisis), esto se torna meramente formal, toda vez que materialmente la decisión de un tribunal inter partes, la que tiene más fuerza mientras más alta la jerarquía judicial, se transforma en una expulsión material del ordenamiento jurídico, aun cuando, en lo formal, la ley declarada en un proceso determinado como contraria a la Constitución, siga formando parte del catálogo de leyes vigentes en el país. Es decir, de la inaplicación en un caso concreto se pasa a la inaplicabilidad general por la regla del precedente. Esto, a pesar de ser una característica básica del sistema de control norteamericano, permite encontrar otro rasgo cercano a su sistema contrapuesto, el europeo, al tener prácticamente la declaración de inconstitucionalidad efectos erga omnes.

De este modo, a pesar de las distintas posiciones orgánicas de cada uno de los organismos que realizan el control de constitucionalidad de las leyes en los modelos clásicos, hoy coinciden en virtud de que ambos constituyen la palabra final en el ordenamiento jurídico respecto a las cuestiones de interpretación constitucional. En Europa el Tribunal Constitucional es concebido como el intérprete supremo de la Constitución, y frente a sus resoluciones de inconstitucionalidad no procede recurso alguno. Por su parte, la Supreme Court norteamericana es la cúspide del sistema judicial, de modo que sus interpretaciones respecto a la inconstitucionalidad informan a todo el ordenamiento jurídico, por el principio del stare decisis.

Ahora bien, el rol de la Suprema Corte de los Estados Unidos, en cuanto tribunal, es fijar la constitucionalidad de las leyes, porlo que encontramos otro elemento que provoca que materialmente el rol de la Suprema Corte de los Estados Unidos se acerque al sistema de control constitucional de los tribunales constitucionales del modelo europeo-kelseniano. Lo anterior, 
en virtud del denominado writ of certiorari o ejercicio discrecional de la jurisdicción, por el que la Corte selecciona aquellos casos de mayor relevancia, que en definitiva son aquellos de rango constitucional, de modo que se difumina en la práctica su posición como tribunal de apelación, pasando, casi exclusivamente, a resolver sobre materias constitucionales o, más bien, sobre constitucionalidad. Este ejercicio de selección se manifiesta no solo como un filtro para no saturar la agenda de la Suprema Corte, sino que es una manifestación de su poder jurisdiccional, decidiendo no decidir, cuando corresponda.

Otra característica que modifica el binomio, o al menos lo atenúa, es la facultad de reponer o devolver la fuerza de ley a normas que habían sido derogadas por leyes que han sido declaradas inconstitucionales, de modo que el Tribunal Constitucional no solo ejercería de legislador negativo sino que también ejercería de legislador positivo; sin embargo, a mí juicio, no ejerce una función creadora de derecho, sino más bien integradora del ordenamiento, toda vez que la norma que revive eventualmente es una que había sido creada y derogada por el Legislativo, de forma tal que no supone una innovación legislativa, sino más bien la reposición de una ley emanada del Legislativo que había sido derogada por otro acto legislativo contrario a la Constitución, es decir, sustituye la voluntad del legislador contraria a la Constitución por otra primitiva decisión de aquel.

Sobre la posición del órgano controlador, las diferencias se han superado de modo tal que lo importante para la introducción de sistemas de justicia constitucional son los fines, es decir, la protección de la Constitución y de los derechos en ella garantizados. Destaca lo anterior A. Celotto cuando sostiene que hoy:
La eficacia de esta garantía (de la libertad y otros derechos fun- damentales) presupone que sea atribuida a otra institución del Estado la competencia necesa- ria para controlar jurídicamente, como instancia final, la conformi- dad a la Constitución de los actos emanados ya sea de los otros poderes o de los sujetos privados. Eso implica la existencia de un órgano especializado de justicia constitucional. Pudiendo éste constituir un tribunal autónomo (no importa su denominación...) o ser una sección especializada de una corte suprema (2004, p. 8).

Otra parte de la doctrina ha sostenido que, en la actualidad, la radical distinción entre los modelos difuso y concentrado se ha aminorado sustancialmente. Ello por la incorporación de mecanismos que permiten al juez que conoce de una causa, y por vía de excepción, representar la posibilidad de inconstitucionalidad que considere puede existir, procedimiento que se conoce como la cuestión de consti-

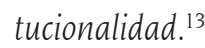

13 La Constitución Española de 1978 lo contempla en su artículo 163: "Cuando un órgano judicial considere, en algún proceso, que una norma con rango de ley, aplicable al caso, de cuya validez dependa el fallo, pueda ser contraria a la Constitución, planteará la cuestión ante el Tribunal Constitucional en los supuestos, en la forma y con los efectos que establezca la ley, que en ningún caso serán suspensivos.". 


\section{NUEVAS HERRAMIENTAS. LA CUESTIÓN DE CONSTITUCIONALIDAD}

A mi juicio, las condiciones del Estado democrático han provocado la aparición de los nuevos modelos de justicia constitucional, lo que no significa que, simplemente, sean una suma de los dos anteriores o clásicos, toda vez que, hoy por ejemplo, el derecho a presentar recursos de amparo ante el Tribunal Constitucional se enmarca en una concepción del Estado que, manifestado en la Constitución, protege los derechos fundamentales de los individuos y, aún más, revela la creciente tendencia a la protección por medio de la interpretación de la Constitución, de los valores y principios que el Constituyente ha querido incorporar, y de la necesaria evolución de dichos principios a la luz de la convivencia democrática con el paso del tiempo.

De acuerdo con lo desarrollado supra, el acercamiento progresivo de los modelos tradicionales de justicia constitucional se manifiesta en determinadas instituciones nuevas, o recursos procesales. La existencia del recurso denominado "cuestión de constitucionalidad", es decir, aquella facultad, o deber en su caso, que tienen todos los jueces de poner en la esfera de conocimiento del órgano encargado de ejercer el control de constitucionalidad, cuando ocurra que el juez que conoce de la causa tenga dudas sobre la constitucionalidad de un determinado precepto legal, es lo que en definitiva viene a poner una gran cortapisa a la polaridad de los dos sistemas clásicos, distorsionando los sis- temas aplicados hasta el momento, ya que combina la actividad del juez que conoce de la causa con la actividad que ejerce el órgano descentralizado que controla la constitucionalidad.

La Constitución austriaca de 1920 establecía que, en el caso de duda sobre la legalidad de un reglamento, el juez que conoce de la causa puede suspender su tramitación a fin de elevar los antecedentes al Tribunal Constitucional, requiriéndole la anulación de dicho cuerpo, por adolecer de un vicio de ilegalidad. La reforma constitucional de 1929 estableció que tanto el Tribunal Supremo como el Tribunal de Justicia Administrativa se encontraban legitimados para plantear el problema de la constitucionalidad de una ley que estuviera siendo objeto de duda en un proceso ventilado ante ellos. Esta solicitud podría ser realizada por cualquiera de las partes intervinientes en el proceso; sin embargo, era exclusiva decisión de los tribunales indicados, quienes resolvían si hacían la solicitud al Tribunal Constitucional. Este derecho directo a las partes, como apunta Fernández (2004, p. 179), entendido como una especie de legitimidad procesal limitada, denominada actio popularis, no otorgaba un derecho directo a los ciudadanos, sino que es por intermedio de otro tribunal como se puede provocar el conocimiento del Tribunal Constitucional.

Lo anterior, con una doble justificación: la una, para permitir a los particulares ejercer una defensa de su derechos en mejores condiciones y mayores garantías; y, la otra, a fin de provocar un filtro en la posibilidad de una avalancha de acciones 
que, meramente dilatorias o infundadas, puedan atraer la atención del Tribunal Constitucional, realizándose así un doble juicio de constitucionalidad, el primero, del tribunal a quo en un proceso de revisión de admisibilidad del recurso, y luego la revisión del Tribunal Constitucional, el que tendría el monopolio de la declaración de inconstitucionalidad.

Lo expresado se ha sostenido debido a que el Tribunal Constitucional, más que un examen de constitucionalidad en las causas sometidas a su conocimiento por la vía de la cuestión de constitucionalidad, ejercería solo la facultad de declarar la inconstitucionalidad, cuestión que no puede hacer el tribunal a quo, pero que habría sido identificada por él, para que se den los presupuestos suficientes para presentar la cuestión al Tribunal Constitucional. Esto se explicaría debido a la doble revisión de fondo, primero del examen de constitucionalidad que todo juez realiza en su labor jurisdiccional, de modo que al provocarle duda, o bien, identificando la inconstitucionalidad de una determinada norma o disposición, dependiendo del sistema, lo somete al Tribunal Constitucional a fin que este, en virtud de sus exclusivas facultades, determine la inconstitucionalidad, provocando los efectos jurídicos que solo el Tribunal Constitucional puede ocasionar en el ordenamiento jurídico.

Aun cuando se comparta el criterio según el cual es el Tribunal Constitucional el titular del monopolio o exclusividad para provocar la expulsión de una norma del ordenamiento jurídico por ser contraria a la Constitución, en el sistema en comento, el examen de constitucionalidad que realiza el tribunal a quo no es determinante para el nuevo examen de constitucionalidad que debe realizar el Tribunal Constitucional. Se podría señalar que lo único que provoca es la ignición de la jurisdicción constitucional en un caso concreto sometido al conocimiento de un órgano judicial. Destaca, de todas formas, la participación en esta materia de las partes, que pudiendo hacer presente al juez que conoce de la causa de una eventual inconstitucionalidad de una norma o disposición legal, le permiten actuar de manera indirecta en la promoción la jurisdicción constitucional, mejorando la protección de sus derechos y garantías constitucionales.

Algunos autores como Pizarruzzo (citado por Fernández, 2004) sostienen que la introducción del mecanismo de cuestión de constitucionalidad para activar la jurisdicción constitucional en los sistemas europeos introduce la incidentalidad, característica del sistema americano, conjugando el sistema difuso con el concentrado. A mi juicio esto solo se verificaría en el momento mismo en que se activa el control constitucional, toda vez que retorna el carácter concentrado, el que se caracteriza por que la decisión de declarar inconstitucional un determinado precepto depende de un órgano único y con efectos generales, sin ser determinante quién lo promovió o cómo se activó su conocimiento para estos efectos.

La importancia de la introducción de la cuestión de constitucionalidad consiste en la innovación en la protección de los de- 
rechos de las personas. Esto, ratificado por la tendencia actual de incorporar otra categoría de justicia constitucional, la que nos permite clasificarla en modelo centrado en la ley y en modelo centrado en la defensa de los derechos. El primero se caracteriza por el tipo de control abstracto; y el segundo, por el control concreto. Así, se sostiene que la tendencia en Europa va en el tránsito desde el primero de ellos hacia el segundo, lo que se ratificaría por la incorporación de la función de defensa de los derechos fundamentales, la que se agrega a las funciones clásicas de control de constitucionalidad de las leyes y la resolución de controversias entre órganos constitucionales ${ }^{14}$.

\section{CONSIDERACIONES FINALES}

1. A pesar de las mixturas entre los modelos clásicos, es conveniente destacar la existencia de características propias que existen entre los distintos sistemas de control de constitucionalidad de las leyes, lo que nos permite distinguir unos de otros, y superar los modelos originarios, asumiendo variables distintas, de manera que hoy cada sistema asume particularidades propias de su desarrollo constitucional.

2. Una de las variables que conviene destacar es la relativa a la temporalidad del control. Esto corresponde

14 T. Groppi (2005) sostiene al respecto que aun cuando se reconoce esta tendencia, se está lejos de constituir un rasgo característico del modelo de justicia constitucional europeo, acercándose más bien a los modelos latinoamericanos. al momento del control de constitucionalidad de una disposición, ya sea previa a su sanción como ley, de modo preventivo o, bien, una vez que ya ha entrado en vigencia, de modo represivo. El control preventivo, como apunta Celotto (2004, p. 8), es resultado de un proceso de intervención del órgano controlador de la constitucionalidad en el proceso legislativo de elaboración de las leyes, toda vez que, aún tiene la posibilidad completa el Parlamento de dictar una ley; es por ello que las críticas de la legitimidad en este caso, a mi juicio, encuentran cierto fundamento, pues las justificaciones, principalmente de economía y celeridad de los procedimientos legales y administrativos, no son suficientes, arrastrando al órgano de control a un espacio de carácter político, dialogante con el Parlamento en el momento mismo de elaboración de una ley, momento de naturaleza política, que le hace perder el carácter de organismo neutral, justificado y garantizado por la forma de conocer del Tribunal Constitucional. Es necesario destacar que el control de tipo preventivo muchas veces se encuentra atenuado al control de ciertos y determinados proyectos, por ejemplo, tratados internacionales, o a determinadas reformas a la Constitución.

3. El control de constitucionalidad de las leyes tiene por objeto dotar de preeminencia a la Constitución sobre toda otra norma o disposición, no por una mera mecánica estructural del sistema, sino por consistir en la manifesta- 
ción de la soberanía popular dentro de un marco de valores y principios que deben prevalecer ante cualquier otra manifestación.

4. Una diferencia importante entre los sistemas de control sobre los que se ha tratado es la naturaleza originaria de la función del control, que en el sistema norteamericano es de carácter judicial, mientras que en el europeokelseniano es considerada con carácter de legislador negativo, toda vez que, teniendo la fuerza de quitar del ordenamiento jurídico una ley, procedimiento inverso del realizado por el Poder Legislativo, el Tribunal Constitucional expulsa con efectos generales una determinada norma.

5. Respecto de los efectos en el tiempo del control de constitucionalidad de las leyes, en el sistema norteamericano la característica es que sus declaraciones tienen efectos retroactivos para las partes (ex tunc), mientras que el carácter del sistema europeo-kelseniano solo dispone para el futuro (ex nunc), lo que es un elemento que reforzaría más aún la idea de legislador negativo en la actuación del Tribunal Constitucional, ya que es el mismo efecto de las leyes.

6. Los efectos ex nunc y ex tunc han sido discutidos en la doctrina, alcanzando parcialmente la regla según la cual los efectos de la declaración de inconstitucionalidad determinan que la ley tiene vicios desde su origen; sin embargo, la expulsión, o nulidad, o declaración de inexistencia tendrán efectos desde la sentencia del Tribunal Constitucional, no pudiendo afectar las sentencias judiciales, ni los procesos terminados en el tiempo intermedio, de modo de no causar estragos en la seguridad jurídica de situaciones particulares que ya se encuentren consolidadas. Como explica con toda claridad Fernández (2004, p. 179), siguiendo a Calamandrei, el juez en el modelo norteamericano no declara la nulidad de una ley por ser inconstitucional, sino que se limita a constatar su inconstitucionalidad de modo que la implica en el caso concreto de que conoce; de allí se extraen sus consecuencias, en tanto sus efectos son relativos solo para la partes $y$, además tiene efectos retroactivos producto del vicio de constitucionalidad de que adolece la ley.

7. La expulsión de una norma del ordenamiento jurídico por disposición del órgano que controla la constitucionalidad, a pesar de tener similares efectos a la derogación de una norma por parte del legislador, se diferencia en la evaluación o examen que se realiza para verificarlo, ya que el legislador realiza un juicio político al modificar o derogar el precepto legal, en cambio la fundamentación de la expulsión por parte del Tribunal Constitucional es de acuerdo con una evaluación de una norma exclusivamente contrastada con el derecho, es decir, de la correspondencia de la ley con la Constitución.

8. Una reciente sentencia, Rol N. ${ }^{\circ} 2777-$ 15, del Tribunal Constitucional de Chile 
(2015), en el voto de prevención de la ministra Marisol Peña, y guardando estrecha relación con el objeto del presente estudio, ha sostenido algunas afirmaciones y preguntas que comparto del todo y considero pertinente dejar como corolario:

\begin{abstract}
Así, la idea de justicia constitucional -una de cuyas expresiones es la existencia de una jurisdicción constitucional concentrada como la que ejerce este Tribunal- obedece a la necesidad de controlar y limitar el ejercicio del poder, objetivo que ha constituido el telos o fin de la Constitución desde los inicios del proceso constitucionalista.
\end{abstract}

En este contexto, cabe preguntarse si existen razones justificadas y potentes para excluir de dicho control a quienes ejercen el poder desde los Parlamentos si, precisamente, son los parlamentarios los llamados a dar vida a las normas de carácter general y obligatorio por las que se va a regir la vida cotidiana de la sociedad. Expresado, en otros términos, ¿es infalible el legislador por el solo hecho de representar la voluntad de la ciudadanía? ¿O, es que el legislador representa y traduce siempre esa voluntad en forma acorde con el pacto social plasmado en la Carta Fundamental?

\section{BIBLIOGRAFÍA}

Almagro Castro, David. 2013. "El modelo español de Justicia Constitucional: Notas para una aproximación". Iurisprudentia, Revista da Faculdade de Direito da Ajes (3): 183 - 207.

Aragón Reyes, Manuel. 2006. "25 Años de Justicia Constitucional en España." En Derecho
Constitucional para el siglo XXI: Actas del VIII Congreso Iberoamericano de Derecho Constitucional. 1st ed. Vol. 2, 3649-3668: Editorial Aranzadi.

Cappelletti, Mauro. 1986. "¿Renegar de Montesquieu?: La expansión y la legitimidad de la "Justicia Constitucional"". Revista Española de Derecho Constitucional 6 (17): 9-46.

Celotto, Alfonso. 2004. "La Justicia Constitucional en el Mundo: Formas y Modelos". Revista Iberoamericana de Derecho Procesal Constitucional (1): $3-14$.

Fernández Segado, Francisco. 2002. La jurisdicción constitucional ante el siglo XXI. Argentina: Discurso de recepción como académico correspondiente en España, Academia Nacional de Derecho y Ciencias Sociales de Córdoba.

Fernández Segado, Francisco. 2004. La justicia constitucional ante el siglo XXI: La progresiva convergencia de los sistemas americano y europeokelseniano. México. UNAM.

García de Enterría, Eduardo. 1988. La Constitución como norma y el Tribunal Constitucional. 3. ${ }^{\text {a }}$ ed. Madrid: Editorial Civitas.

Garrorena Morales, Ángel. 2015. Escritos sobre la democracia: la democracia y la crisis de la democracia representativa. Madrid: Centro de Estudios Políticos y Constitucionales.

Groppi, Tania. 2005. "¿Existe un modelo europeo de Justicia Constitucional?" Revista de Derecho Político (62): 33-54.

Hamilton, A., Madison, J. E Jay, J. 2001. El Federalista. México: Fondo de Cultura Económica.

Kelsen, Hans. 1949. General Theory of Law and State. Cambridge: Harvard University Press.

Locke, John. 2002. Segundo tratado sobre el gobierno civil: un ensayo acerca del verdadero origen, alcance y finalidad del gobierno civil. Buenos Aires: Losada. 
Lucas Verdú, Pablo. 1986. Curso de derecho político. Madrid. Ed Tecnos.

Nogueira Alcalá, Humberto. 2015. El bloque constitucional de derechos en Chile, el parámetro de control y consideraciones comparativas con Colombia y México: doctrina y jurisprudencia. Estudios Constitucionales, 13 (2), 301-350.

Peña Torres, Marisol. 2014. La legitimidad de la justicia constitucional en un sistema democrático. Ponencia presentada en la $\mathrm{X}$ Conferencia Iberoamericana de Justicia Constitucional, realizada en la ciudad de Santo Domingo, República Dominicana, el 14 de marzo de 2014. <http://www.cijc.org/ conferencias/StoDomingo2014/Documents/ Conferencia\%20de\%20la\%20Presidenta\%20 del\%20Tribunal\%20 Constitucional\%20 de\%20Chile.pdf> [Verificado 03-11-2015].

Peña Torres, Marisol. 2012. "Los desafíos del Derecho Constitucional desde la perspectiva de la Justicia Constitucional". En Silva, María y Henríquez, Miriam (coordinadoras): Derechos fundamentales y justicia constitucional ¿consolidación o reforma? Santiago: Thomson Reuters.

Pérez Royo, Javier. 1988. Tribunal constitucional y división de poderes. Madrid: Tecnos.

Pérez Royo, Javier. 1987. La Reforma de la Constitución. Vol. 9. Madrid: Publicaciones del Congreso de los Diputados.
Rousseau, Dominique. 2002. La justicia constitucional en Europa. Madrid: Centro de Estudios Políticos y Constitucionales.

Rawls, John. 1993. Teoría de la justicia. Buenos Aires: Fondo de Cultura Económica.

Schmitt, Carl E Kelsen, Hans. 2009. La Polémica Schmitt/Kelsen sobre la Justicia Constitucional "El Defensor de la Constitución", contra ¿Quién debe ser el Defensor de la Constitución? Madrid: Tecnos.

Schneider, Hans-Peter. 1982. "Jurisdicción Constitucional y Separación de Poderes". Revista Española de Derecho Constitucional 2 (5): 35-62.

Suprema Corte U.S. 1803. Marbury contra Madison. 5 U.S. 1 Cranch 137. <https://supreme.justia. com/cases/federal/us/5/137/case.html> [Verificado 21-1-2015].

Tribunal Constitucional de Chile. 2015. Sentencia Rol N. ${ }^{\circ} 2777-15$.

Vile, M. J. C. 2007. Constitucionalismo y separación de poderes. Madrid: Centro de Estudios Políticos y Constitucionales.

Zagrebelsky, G. 1995. El derecho dúctil. Trad. de Marina Gascón. Madrid: Ed. Trotta. 